negativos: reducir el período de la estabilización fiscal porque enfría los ímpetus
estabilizadores de los gobiernos (corto y mediano plazo), y la necesidad de generar superávit en el futuro para pagar la deuda puede ocasionar expectativas de menor crecimiento por alzas de impuesto y/o reducción del gasto (largo plazo). Ambos resultados orientan a pensar que la
recuperación mundial estaría lejos de ser recuperación mundial estaría lejos de ser
robusta y sin mejorias sustanciales en la robusta y sin mejorias sustanciales en la
productividad, y como ha señalado recientemente Kenneth Rogoff -ex economista jefe lúcidos en temas internacionales-, el despegue del mundo después de esta crisis es pegue del mu
una incógnita.

UNA NUEZ EN EL OCÉANO

China sigue funcionando cómo único motor para que el mundo no termine hundiéndose. Sin embargo, ¿cuanto más
podemos confiar en este gigante económipodemos confiar en este gigante económi-
co si sus mercados de exportación siguen mostrando debilidades por todos los flancos? ¿Será cierto que su mercado interno absorbiendo recursos y elevando el precio de las materias primas como el cobre, maíz, arroz o petróleo? Un tema aparte es que la demanda dinámica de China está produciendo un efecto colateral: el alza en el precio de los alimentos. Las economias en todas las regiones no solo tienen que soportar un alto desempleo, sino tambien altos precios en los alimentos: una El desorden en estos merendos pueste lievar a los bencos centrales a confundise por el aumento de la inflación y gatillar aumentos de tasas, y con ello más incertidumbre. Sin duda que es momento no solo de pensar en regular los mercados
Inancieros después de la debacle sino, monetaria, y por tanto la economía tendía mbién los mercados de materias primas, a recuperarse a través de un aumento de ya incierto escenario internacionel.

Cuesta entender a veces este exceso ptimismo en las proyecciones, puesto que la economía chilena siempre ha sido qua nuez en un océano turbulento. Más ra vez resultan ser la mejor proyecció de que la economia entrará en los vaiverisis, se ha orgumentado que la economí chilena no se verá afectada. Y lo que ha currido es que el ciclo económico internacional toma su tiempo, pero llega a $\mathrm{Chi}$ e más temprano que tarde. Así, un estudio ${ }^{1}$ del Banco Central de Chile encuentra que el PIB de Chile estaría asociado conemporaneamente con el PIB de América Latina, China y socios comerciales. Un punto clave en este estudio es que se enprester mestres a Furopa Janón y América Latina. s. cae, como en un dominó, lo sigue Europa, Japón, los socios comerciales y finalmente nuestra economía. El dato clave consiste tres trimestres.

Mis calculos realizados con $\mathrm{ALMA}^{2}$ indican que si la economia internacional crece thato monos de lo esperado, la econo. ropiezo de la recuperación mudial nos puede llevar a un crecimiento por debajo del 4\%. Las regularidades empíricas señaan que la economía sufre en dos frentes: menos consumo y menos empleo. En pasado una caída de la actividad mundia evaba a una caida de la tasa de política nás bajas. sideran un elemento esencial de la última recesión: la falta de confianza de los gentes en nuestra economía. Este elemento acelero el ciclo internacional sobre a economia chilena, tanto que la inver. cespectavasta vas de los empresarios sobre el futuro de nuestra economía serán optimistas y esta percepción, como sabemos, se puede derrumbar y arrastrar a la economía hacia el despeñadero. En resumen: una caíd abrupta de las expectativas puede acenuar el ciclo economico y demorar la anhelada recuperación con menos consumo, inversión y -lo más doloroso- una tasa de Por eso, la política fiscal y Don hasta que los nubarrones sobre el escenade optimismo puede llevar a pensar que la repetir algunos errores del pasado, como la reacción a la crisis asiatica, que llevo que la economia no sólo se deprimiera por el shock externo, sino tambièn por que sólo agravaron la sicas contractivas plejidad del niveles de incertidumbre son tan latos que es necesario actuar con cautela. Las autoridades de gobierno deben sin duda presionar al alza de las expectativas ecohómicas, pero también tener mesura.
Pero los resultados de ALMA no contio internacional desaparezcan. Un exceso economía está sobrecalentada y con ello

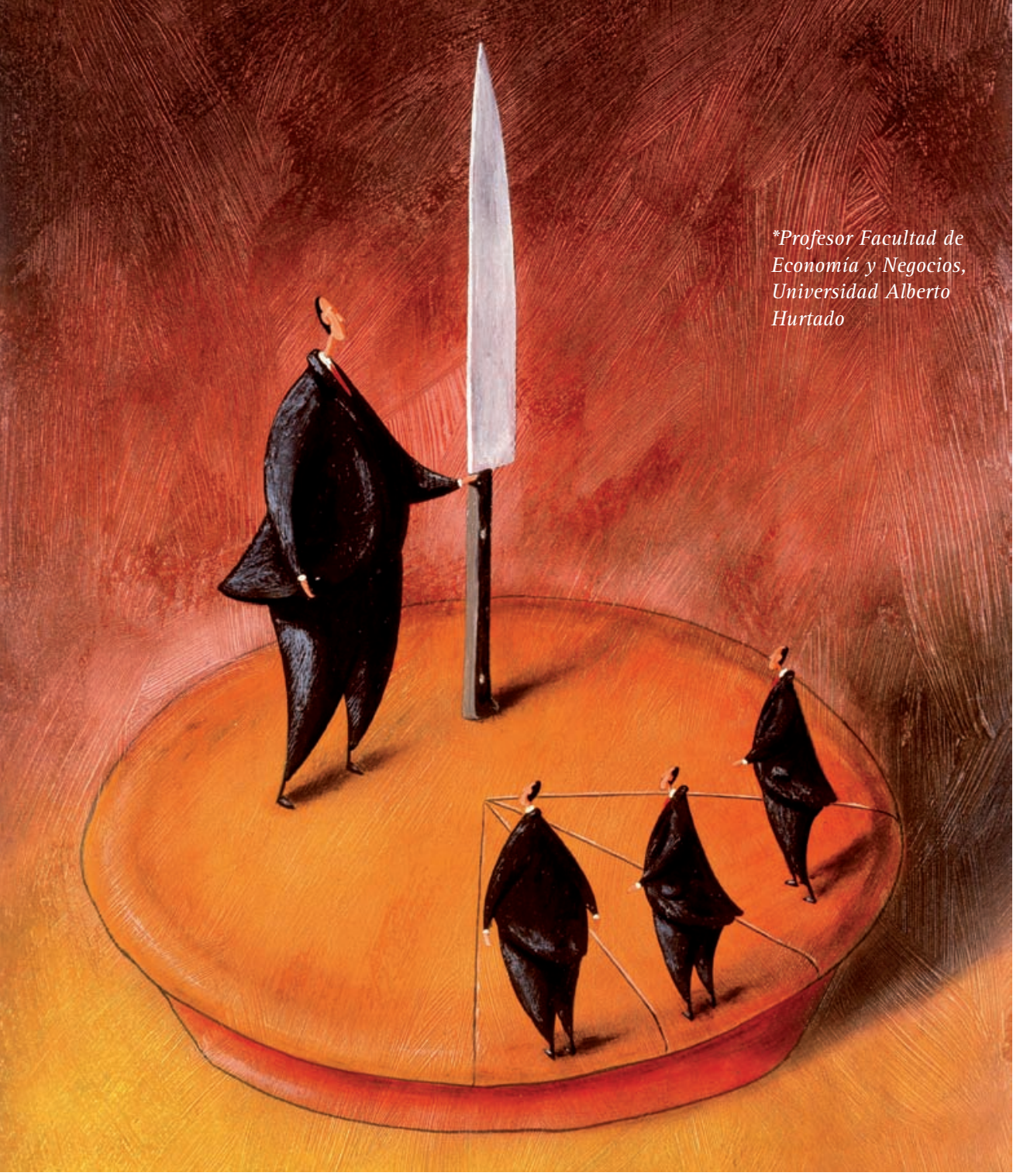

\section{La distribución silenciosa}

Juan Foxley Rioseco

Hay algo curioso e impreciso en hablar generalmente sobre datos de ingreso al referirs mas de hacerlo es que incluso si ses problelos ingresos totales (autogenerados más transferencias monetarias del gobiernol se queda fuera los usos de servicios subsidiados Pero un segundo problema se manifiesta cuando queremos tener una idea de distribución de riqueza en distintos momentos del ciclo económico. Es conocido que la dotación de capital hu-

mano (el capital fisico y financiero, vis a vis) condiciona ciertos tipos de distribución del 1 el precario capital de sus poco entrenadadas no solo mayor educación sorino frecuntos tienen te alguna porción de riqueza en la forma de bienes inmuebles 0 instrumentos financieros. Cierto es que los más pobres podrian ten también alguin saldo invertido en acciones, Distribución de ingreso y precios de activos

\begin{tabular}{|c|c|c|c|c|}
\hline Año & $\begin{array}{l}\text { Ingreso decil más } \\
\text { pobre (miles pesos } \\
\text { constantes) }\end{array}$ & $\begin{array}{l}\text { Ingreso decil más } \\
\text { rico (miles pesos } \\
\text { constantes) }\end{array}$ & $\begin{array}{l}\text { Indice general de } \\
\text { precios de acciones } \\
\text { en términos reales } \\
\text { (base dic. 2006) }\end{array}$ & $\begin{array}{l}\text { Tasa de interés real } \\
\text { de captación } 90 \text { dias } \\
\text { a un año }\end{array}$ \\
\hline $\begin{array}{l}2009 \\
2006\end{array}$ & $\begin{array}{l}114 \\
113\end{array}$ & $\begin{array}{l}2953 \\
2705\end{array}$ & $\begin{array}{l}16630,91 \\
14197,70\end{array}$ & \\
\hline Variación \% & \begin{tabular}{|l|}
0,9 \\
\end{tabular} & 9,2 & 17,1 & 2,57 \\
\hline
\end{tabular}

en una APP, pero no pasarian de ser episodios puntuales por montos insignificantes como

Pues bien, si la capacidad de generar ingreso depende de un capital humano infimo, económicos recesivos estanquen el ingreso de los más pobres cuando los puestos de trabajo se hacen inestables o más dificicles de obtener. Es lo que mostró la encuesta Casen para los ingresos autónomos del decil más pobre de la población.

A su turno, los segmentos de mayor ingreso pueden defender sus empleos con capital humano en la forma de habilidades especificas, precisamente aquellas que son mas caras de de despedir.

Sin embargo, y si de capacidad de generar renta se trata, debe observarse como factor adicional el que los segmentos más ricos se pueden beneficiar, además de ganancias de capital por la posesion de activos fisicos o finandiros. Nada de esto es captado por encuestas

nes depreciadosa, por la valorización de bieobservar durante la salida de las fases de caida en la activided ecońmica. Es lo que paree haber ocurrido en Chile durante 2009 cuando comienza a anticiparse el fin de la crisis de crédito del año anterior. Los precios de los activos se recuperaron con fuerza después de haber Asi y para tomar una variable proxy del precio de los activos distintos del capital humano, podemos observar el indice IGPA de las acciones transadas en la mayor bolsa chilena. Los precios se recuperan en 2009 y quedan, en cuadrol, en un contexto de tosas de intés ber jas que hace atractiva la compra de inmuebles

Resultado: las ganancias de capital muestran un aumento entre 2006 y 2009 que casi duplica el de los ingresos reportados por el decil más rico en la encuesta Casen sobre ingresos autónomos.

Oe Decano: Jorge Rodriguez Grossi.
Fono Facultad: 8897366 e-mail: jrodrigu@uahurtado.cl
economiannegociossuahurtadocll/observatorio
Producción OE: Comunicar, Escuela de
Periodismo UAH.
OE es una revista de circulación gratuita. 